ARTICLE HISTORY: Received: September 13, 2021 Accepted: November 5, 2021 Published: November 13, 2021

РОЛЬ СОВРЕМЕННОЙ ФРАНЦУЗСКОЙ ЭКОНОМИКИ В ЕС

Горбунова Наталья Евгеньевна

студентка

Московский государственный университет им. Ломоносова,

Москва, Россия

\title{
THE ROLE OF THE MODERN FRENCH ECONOMY IN THE EU
}

Gorbunova N.E.

student

Lomonosov Moscow State University, Moscow, Russia

\begin{abstract}
Аннотация. Целью статьи является исследование экономических отношений Франции на территории ЕС и её влияния на экономическое развитие союза в целом.

Предмет и методы. Теоретико-методологическую базу исследования составляют основные экономические законы; фундаментальные труды отечественных и зарубежных ученых-экономистов по проблематике экономической интеграции. В работе используются соответствующие законодательные и нормативные акты общеевропейского, государственного и регионального уровня, а также труды ученых смежных дисциплин демографов, социологов, правоведов. Были использованы следующие методы: статистический анализ, факторный анализ, сравнительный анализ, системный метод, сравнительно-исторический анализ и другие.

Результаты исследования. Автором впервые была дана систематизация этапов формирования современной социально-экономической модели Франции. Обозначены проблемы, степень экономического влияния и место Пятой Республики в экономических процессах интеграционного объединения.

Обсуждение. Роль государства в Европейском союзе постепенно увеличивается, но ситуация усугубляется кризисом на фоне распространения коронавирусной инфекции и подрывом национальной экономики Франции на фоне коллапса глобальных экономических связей. Видение Франции и Германии в вопросе исцеления экономической системы ЕС значительно разнятся.

Заключение. Франция пытается восстановить свое геополитическое положение по отношению к Германии с помощью нововведений в экономическое устройство ЕС, которые включают в себя целый ряд идей о том, как исцелить интеграционное объединение, и пытается доминировать в европейской повестке дня на геополитическом и геоэкономическом уровне. Однако, экономическая активность страны находится в упадке на данный момент.
\end{abstract}

Abstract. The purpose of the article is to study the economic relations of France on the territory of the EU and its impact on the economic development of the union as a whole.

Subject and methods. The theoretical and methodological basis of the research consists of the main economic laws; fundamental works of domestic and foreign scientists-economists on the problems of economic integration. The work uses the relevant legislative and regulatory acts of the pan-European, state and regional level, as well as the works of scientists of related disciplines - demographers, sociologists, jurists. The following methods were used: statistical analysis, factor analysis, comparative analysis, system method, comparative historical analysis and others.

The results of the study. The author for the first time gave a systematization of the stages of the formation of the modern socio-economic model of France. The problems, the degree of economic influence and the place of the Fifth Republic in the economic processes of the integration association are identified.

Discussion. The role of the state in the European Union is gradually increasing, but the situation is aggravated by the crisis against the background of the spread of coronavirus infection and the undermining of the national economy of France against the background of the collapse of global economic ties. The vision of France and Germany on the issue of healing the EU economic system differs significantly.

Conclusion. France is trying to restore its geopolitical position in relation to Germany with the help of innovations in the economic structure of the EU, which include a number of ideas on how to heal the integration association, and is trying to dominate the European agenda at the geopolitical and geo-economic level. However, the country's economic activity is in decline at the moment.retains its position and is second only to Germany in terms of stability within the European Union.

Ключевые слова: Французская республика, Европейский союз, интеграция, COVID-19, международная экономика, экономическое развитие, транснациональные компании.

Key words: French Republic, European Union, integration, COVID-19, international economy, economic development, multinational companies. 


\section{1. ВВЕДЕНИЕ}

Пятая Республика была одним из идейных вдохновителей создания европейского интеграционного объединения, и спустя практически 70 лет существования ЕС она продолжает придерживаться идеи интеграции европейских государств [3]. Французская промышленность, агропромышленный комплекс, банковская сфера, финансы «вшиты» в канву Европейского союза и не могут существовать по отдельности. Европейский Союз включает в себя страны с различным экономическим потенциалом, и на примере Франции можно дать оценку степени влияния отдельного государства-члена ЕС на экономическую ситуацию Союза в целом.

Целью данной статьи является исследование экономических отношений Франции на территории ЕС и еѐ влияния на экономическое развитие союза в целом.

\section{2. МЕТОДЫ ИССЛЕДОВАНИЯ}

Эмпирическую базу исследования составили основополагающие документы Европейского союза; законодательные, нормативные, правовые акты Франции, использовались материалы официального сайта Министерства Внутренних дел Франции (Le site officiel du ministère de l'Intérieur de l'Outre-mer et des Collectivités Territoriales) [13] и сайта Министерства Иностранных дел Франции (Le ministère de l'Europe et des Affaires étrangères) [12]. Статистические данные международных организаций (Международная организация труда (MOT) [8, С. 29-52], Европейский Союз (ЕС), Всемирный банк [14]. данные Национального центра научной статистики [10], Национального института статистики и экономических наук [9], Eurostat [6].

\section{3. РЕЗУЛЬТАТЫ ИССЛЕДОВАНИЯ}

После Второй мировой войны Франция прошла многоступенчатый путь от директивного планирования к стратегическому (с 1990-х), состоявший из одиннадцати этапов (экономических планов). Введение подобной системы позволило увеличить влияние государства на экономику и привело к образованию мощного государственного сектора в экономике страны. Франция - крупный игрок в мировой торговле. Она является шестым в мире экспортером и импортером товаров по данным ВТО, а торговля составляет более $65 \%$ ВВП страны.

Одна пятая сельскохозяйственного производства всего Евросоюза приходится на Францию, поэтому страна считается одной из наиболее крупных аграрных держав в ЕС, кроме того она является полностью самообеспеченной сельскохозяйственной продукцией. Но, не смотря на этот факт, сектор сельского хозяйства является самым маленьким в общем объёме ВВП - всего 1,6\%, а занятость населения в нём не превышает $3 \%$. Европейский Союз оказывает значительную финансовую поддержку сельскохозяйственной деятельности Франции. Но даже при этом, сельхоз сектор экономики Франции демонстрирует постепенное снижение (с 2007 г. Объёмы производства снизились больше чем на 15\%). Основными продуктами сельхоз производства Республики являются вино, сыры, мясо, кукуруза и пшеница.

Второй по значимости сектор экономики страны - это промышленность (17,1\% ВВП). Занятость населения в промышленности намного больше чем в сельском хозяйстве и достигает почти $20 \%$ от рабочей силы станы. В настоящее время страна переживает деиндустриализацию, поэтому, не смотря на большое разнообразие направлений обрабатывающей промышленности, многие из видов деятельности были переданы на аутсорсинг. Страна всё ещё занимает лидирующие позиции в автомобилестроении, вооружении, аэрокосмической промышленности, пищевой промышленности, химической промышленности, а также в производстве электроники среди стран-участниц ЕС [2, С. 304-336].

Наиболее значимым же сектором экономики страны является третичный. Он обеспечивает более $70 \%$ экономики страны, в таких же объемах он представляет возможность трудоустройства для экономически активного населения. Из всех отраслей сферы услуг наиболее значимой можно назвать туристическую. Эта отрасль по своей прибыльности достигает почти $10 \%$ ВВП и обеспечивает занятость примерно двух миллионов людей. Франция закрепила за собой статус наиболее популярного туристического направления во всём мире. Ежегодно родину Марсельезы посещают в среднем 90 миллионов человек. По уровню прибыльности французская туристическая сфера занимает 3 место в мире. Культурное и историческое наследие страны, уникальные произведения искусства, кулинарные изыски, потрясающая природа и шопинг - вот что так привлекает людей со всех уголков планеты [11].

Таблица 1.

Разбивка экономической деятельности Франции по секторам, \% [7]

\begin{tabular}{|c|c|c|c|}
\hline Разбивка экономической деятельности по секторам & Сельское хозяйство & Промышленность & Услуги \\
\hline Занятость по секторам (в \% от общей занятости) & 2.4 & 19.9 & 77.7 \\
\hline Добавленная стоимость 2019 г. (в \% ВВП) & 1.6 & 17.1 & 70.2 \\
\hline Добавленная стоимость (ежегодное изменение в \%) & -0.3 & 0.7 & 0.1 \\
\hline
\end{tabular}


Очевидно, что в 2020 году из-за пандемии COVID-19 меры изоляции привели к беспрецедентной потере активности практически во всех секторах. Наиболее сильно пострадал туризм, автомобильная промышленность, транспорт и авиакосмическая промышленность, в то время как агропродовольственный и фармацевтический секторы оказались устойчивыми.

Несмотря на усилия правительства по поощрению инноваций, французский экспорт имеет относительно низкую добавленную стоимость. В 2019 году торговый дефицит без учета услуг достиг 52,1 миллиарда долларов США. Согласно последним данным, опубликованным INSEE (Points de Conjoncture, декабрь 2020 г.), в 2020 г. экспорт товаров и услуг снизился на -18 \% по сравнению с 2019 г., в то время как импорт снизился на $-11 \%$, внешняя торговля не принесла положительных результатов из-за последствий пандемии [4]. Выход Великобритании из ЕС стал для французской элиты стратегической возможностью продвигать собственное видение европейской экономической системы. Еще один призыв к политическому наступлению - смена политических поколений в Германии. Дальнейшие трудности, включая растущее расхождение между Парижем и Берлином и сопротивление со стороны некоторых других стран-членов ЕС даже вдохновляют Эммануэля Макрона на все более активные действия [5].

Президент Франции стремится структурно реорганизовать внутренний рынок [11]. В своей знаменитой речи в Университете Сорбонны в 2017 году Макрон представил основные цели реформы еврозоны. Он поддержал идею бюджета и министра финансов еврозоны, чтобы увеличить структурные инвестиции и стимулировать экономический рост. Кроме того, создание отдельного бюджета зоны евро позволит обеспечивать ее стабильность в случае возникновения кризисных ситуаций. Он пришел к выводу, что бюджет еврозоны должен пополнятся в первую очередь за счет европейских налогов (и, как следствие, быть независимым от влияния крупнейшего потенциального спонсора - Германии). Более того, французские эксперты также добавляют к этому необходимость создания общих облигаций еврозоны, которые могли бы обеспечить безопасность для растущего государственного долга в валютном союзе и увеличить тем самым государственные инвестиции.

\section{4. ДИСкУССИЯ}

В последние годы франко-немецкий «мотор» явно дал сбой, и все больше и больше споров возникает между французским и немецким видением будущего ЕС. Это, по сути, заставляет Макрона искать нестандартные способы действий и все чаще ставить немцев в неудобное положение, когда он пытается в одностороннем порядке формировать европейскую повестку дня. В странах, недавно пострадавших от пандемии также значительно увеличились государственные долги. Так долг Франции, у которой с момента введения евро коэффициент государственного долга стабильно был ниже 100\%, в сентябре 2020 года достиг 115\% (Insee) [4]. Эти данные связаны с резким сокращением ВВП в 2020 году, например -12,8\% для Испании и Италии, а также $-8,2 \%$ для Франции. Эти проценты превысили средний прогноз упадка для еврозоны, и становится очевидным, что решение какой-либо страной экономических проблем еврозоны невозможно, пока не будут решены национальные.

\section{5. ЗАКЛЮЧЕНИЕ}

В ходе исследования сделаны выводы о том, что Франция пытается восстановить свое геополитическое положение по отношению к Германии с помощью нововведений в экономическое устройство ЕС, которые включают в себя целый ряд идей о том, как исцелить ЕС, и пытается доминировать в европейской повестке дня на геополитическом и геоэкономическом уровне.

Вот почему немецкие политики подозревают, что Макрон стремится заменить немецкое экономическое руководство французским. Роль государства в Европейском союзе постепенно увеличивается, но ситуация усугубляется кризисом на фоне распространения коронавирусной инфекции и подрывом национальной экономики Франции на фоне коллапса глобальных экономических связей. Государству потребуются колоссальные материальные затраты на выход из кризиса и реабилитацию экономической и финансовой систем. Ситуация усугубляется тем, что не существует однозначных прогнозов о сроках выхода из кризиса, что не позволяет планировать развитие мировой экономики. Первоочередной задачей французской экономики на данный момент является обеспечение нужд государства и нации в чрезвычайной ситуации, вопрос о месте Франции в Европейской Союзе и необходимости перемен станет одной из приоритетных задач, стоящих перед французским правительством и Францией в целом по мере стабилизации международной обстановки.

\section{СПИСОК ИСПОЛЬЗОВАННЫХ ИСТОЧНИКОВ}

1. Зверева Т.Ю. Основные направления внешней политики Франции в условиях глобализации: дис. д-ра полит. наук. Москва, 2014. С. 446 11. Солиев Р.А. История формирования Европейского союза // Ученые записки Худжандского государственного университета им. академика Б. Гафурова. Гуманитарные науки. 2018. №1. C. 65.

2. Комиссарова Ж. Н., Сергеев Е. А. Промышленная политика Франции // В кн.: Промышленная политика. - М.: КноРус, 2020. - С. 304-336. 
3. Солиев Р.А. История формирования Европейского союза // Ученые записки Худжандского государственного университета им. академика Б. Гафурова. Гуманитарные науки. 2018. №1. С. 65.

4. Economic outlook - 15 December 2020. INSEE. 2020. [Электронный pecypc] URL: https:/www.insee.fr/en/statistiques/5006924?sommaire=4473307 (дата обращения: 18.02.2021).

5. Emmanuel Macron: Dear Europe, Brexit is a lesson for all of us: it's time for renewal. 2019. The Guardian. [Электронный pecypc] URL: https://www.theguardian.com/commentisfree/2019/mar/04/europe-brexit-uk (дата обращения: 18.02.2021).

6. Exports of goods and services in \% of GDP // Eurostat. - 2021. [Электронный pecypc] URL: https://ec.europa.eu/eurostat/databrowser/view/tet00003/default/bar?lang=en (дата обращения: 08.03.2021).

7. France: Distribution of gross domestic product (GDP) across economic sectors from 2009 to 2019 // Statista. [Электронный ресурс] URL: https:/www.statista.com/statistics/270352/distribution-of-gross-domestic-product-gdpacross-economic-sectors-in-france/ (дата обращения: 16.02.2021).

8. ILO Global Estimates on International Migrant Workers - Results and Methodology. 2nd ed. // International Labour Office. - 2018. - P. 29-52.

9. L'internationalisation des enterprises et l'économie française // INSEE. [Электронный pecypc] URL: http://www.insee.fr/fr/ffc/docs_ffc/ENTFRA13b_D1_mondialisation.pdf (дата обращения 08.02.2021).

10. Le Centre national de la recherche scientifique. [Электронный ресурc] URL: http://www.cnrs.fr (дата обращения 01.04.2021).

11. Le programme d'Emmanuel Macron pour l'Europe. Une Europe qui protège les Européens. [Электронный pecypc]. - Режим доступа: https://enmarche.fr /emmanuel-macron/le-programme/europe. (дата обращения: 26.02.2021).

12. Le tourisme en France // Le ministère de l'Europe et des Affaires étrangères. [Электронный pecypc] URL: https://www.diplomatie.gouv.fr/ru/politique-etrangere/turizm/ (дата обращения: 16.02.2021).

13. Ministere de l'Interieur. Organisation. [Электронный pecypc] URL: https://www.interieur.gouv.fr/Leministere/Organisation (дата обращения 04.04.2021).

14. World Bank Open Data. [Электронный pecypc] URL: https://data.worldbank.org/ (дата обращения: 04.04.2021). 